\title{
Synthesis, structure and thermal stability of a mesoporous titanium(III) amine containing MOF with improved hydrogen sorption properties
}

\author{
Timothy Steenhaut, ${ }^{\text {a }}$ Séraphin Lacour, ${ }^{\mathrm{a}}$ Gabriella Barozzino-Consiglio, ${ }^{\mathrm{a}}$ Koen Robeyns, ${ }^{\mathrm{a}}$ Robin \\ Crits, ${ }^{a}$ Sophie Hermans ${ }^{* a}$ and Yaroslav Filinchuk ${ }^{* a}$ \\ ${ }^{a}$ Université Catholique de Louvain, MOST, Place Louis Pasteur 1, 1348 Louvain-la-Neuve, Belgium \\ E-Mail : timothy.steenhaut@uclouvain.be; sophie.hermans@uclouvain; yaroslav.filinchuk@uclouvain.be
}

\begin{abstract}
The first mesoporous bimetallic $\mathrm{Ti}^{\mathrm{III}} / \mathrm{Al}$ metal-organic framework (MOF) containing amine functionalities on its linkers has been selectively obtained by converting the cheap commercially available $\left(\mathrm{TiCl}_{3}\right)_{3} \mathrm{AlCl}_{3}$ into $\mathrm{Ti}_{3-\mathrm{x}} \mathrm{Al}_{\mathrm{x}} \mathrm{Cl}_{3}(\mathrm{THF})_{3}$ and reacting this complex with 2-aminoterephthalic acid in DMF under soft solvothermal conditions. This compound is structurally related to the previously described $\mathrm{NH}_{2}-\mathrm{MIL}-101(\mathrm{M})(\mathrm{M}=\mathrm{Cr}$, Al and $\mathrm{Fe}) \mathrm{MOF}$. Thermal gravimetric analyses and in situ PXRD measurements demonstrated that this highly air-sensitive $\mathrm{Ti}^{\mathrm{III}}$-containing MOF is structurally stable up to $200^{\circ} \mathrm{C}$. Nuclear magnetic resonance (NMR) spectroscopy, elemental and inductively-coupled plasma (ICP) analyses revealed that $\mathrm{NH}_{2}-\mathrm{MIL}-101\left(\mathrm{Ti}^{\mathrm{III}}\right)$ contains trinuclear $\mathrm{Ti}_{3}\left(\mu_{3}-\mathrm{O}\right) \mathrm{Cl}(\mathrm{DMF})_{2}(\mathrm{RCOO})_{6}$ clusters with strongly bound DMF molecules, and a small amount of aluminum. Sorption experiments reveal a higher affinity of this MOF for hydrogen compared to the previously described monometallic unfunctionalized MIL-101( $\left.\mathrm{Ti}^{\mathrm{III}}\right) \mathrm{MOF}$.
\end{abstract}




\section{Introduction}

Metal-organic frameworks, also known as MOFs, are well-established materials with currently over 90.000 experimentally obtained structures and over 500.000 predicted ones. ${ }^{1}$ The most interesting feature of such compounds, formed by the interconnection of metal centers or clusters through organic bridging linkers, ${ }^{2}$ is that they can possess permanent porosity, enabling many applications in adsorption, separation and catalysis, among others. ${ }^{3,4,5,6,7}$

Amidst the vast variety of existing MOFs, the ones with the so-called MTN topology are particularly interesting. The topology of those frameworks is derived from that of the zeolite Socony Mobil Thirthy-Nine (ZSM-39) ${ }^{8}$ and consists of the assembly of two types of large interconnected mesopores that are accessible through hexagonal and pentagonal windows (Figure 1, A and B). The vast majority of those MOFs (although a few exceptions are known) ${ }^{9}$ are built from trinuclear $\mathrm{M}_{3}-\mu_{3}$-oxo clusters bearing six carboxylate functions from the organic linkers and additional anions $\left(\mathrm{F}^{-}, \mathrm{OH}^{-}, \mathrm{Cl}^{-}\right.$, etc.) for charge balancing when needed, together with solvent molecules to complete the coordination spheres of the metal centers (Figure 1, C). The linkers interconnect four metal cluster units to form microporous supertetrahedra of which they form either edges or faces, depending on whether they are ditopic or tritopic (i.e. linkers having two or three carboxylate functions), ${ }^{10}$ respectively. The most representative members of this series of MOFs are MIL-101(M) and MIL-100(M), built respectively from terephthalate $\left(\mathrm{BDC}^{2-}\right)$ or trimesate $\left(\mathrm{BTC}^{3-}\right)$ linkers (Figure 1, D and E) and containing chromium, ${ }^{11,12}$ iron $^{13,14}$ or aluminum ${ }^{15,16,17}$ as metal centers. Several reports also mention the use of vanadium, ${ }^{18,19}$ indium, ${ }^{20}$ manganese, ${ }^{21}$ scandium $^{22}$ or, more recently, titanium(IV) ${ }^{23}$ or the combination of several metals (e.g. $\mathrm{Ni}^{2+}, \mathrm{Co}^{2+}, \mathrm{Zn}^{2+}$ or even lanthanides) $)^{24,25,26}$ for the construction of such frameworks. However, there are very few reports of MTN MOFs containing titanium in the + III oxidation state, ${ }^{27,28,29}$ or more generally reports concerning the incorporation of $\mathrm{Ti}^{\mathrm{III}}$ in metal-organic frameworks, ${ }^{30,31,32}$ although $\mathrm{Ti}^{3+}$ open metal centers in other type of materials are known to be efficient sites for hydrogen sorption, catalysis or other applications. ${ }^{33,34,35,36}$

Mason et al. obtained the first Ti ${ }^{\mathrm{III}}$-based MOF, MIL-101(TiII) (Figure 1, C), in 2015 by using a solvothermal approach consisting of heating $\mathrm{H}_{2} \mathrm{BDC}$ and $\mathrm{TiCl}_{3}$ in a 10:1 mixture of DMF and ethanol. ${ }^{27}$ The obtained purple solid was shown to be crystallographically pure MIL-101( $\mathrm{Ti}^{\mathrm{III}}$ ) having the chemical formula $\mathrm{Ti}_{3} \mathrm{O}(\mathrm{OEt})(\mathrm{BDC})_{3}(\mathrm{DMF})_{2}$, DMF being partly exchangeable by $\mathrm{THF}$. 
This MOF was not only the first reported $\mathrm{Ti}^{\mathrm{iII}}$-based one, but was also the first ever described compound containing carboxylate-bridged titanium-oxo clusters of the $\mathrm{Ti}_{3} \mathrm{O}\left(\mathrm{O}_{2} \mathrm{CR}\right)_{6} \mathrm{~L}_{3}$ type (Figure 1, A). Activation of MIL-101( $\mathrm{Ti}^{\mathrm{iII}}$ ) by washing with $\mathrm{THF}$ followed by heating at $150^{\circ} \mathrm{C}$ allowed to remove coordinated solvent molecules from one out of three Ti centres, creating openmetal sites, whereas washing the MOF with methanol or ethanol instead of THF led to decomposition of the framework. Furthermore, the activated MOF showed high and irreversible reactivity with oxygen by forming peroxide and superoxide species, evidencing its particular sensitivity.

After this first investigation, the area of $\mathrm{Ti}^{\mathrm{iII}}$-based MOFs remained largely unexplored, likely due to their air-sensitive nature. However, quite recently, Antonio et al. developed a procedure based on the in-situ generation of $\mathrm{TiCl}_{3}$ as precursor for the synthesis of such compounds. ${ }^{28}$ This procedure was first used to synthesize MIL-101( $\left.\mathrm{Ti}^{\mathrm{III}}\right)$, by electrochemically reducing $\mathrm{TiCl}_{4}$, which is cheaper and available in higher purity grades than commercial $\mathrm{TiCl}_{3}$. This was carried out in a mixture of $\mathrm{DMF}$ and ethanol in the presence of terephthalic acid and $\mathrm{NBu}_{4} \mathrm{PF}_{6}$ as electrolyte. The obtained solution with the freshly generated $\mathrm{Ti}^{3+}$ was then solvothermally treated to yield the desired MOF. In their study, the authors also extended their synthetic approach to various other MOFs with the MTN topology having tritopic and extended linkers. In this way, they were able to obtain MIL-100(Ti ${ }^{\mathrm{III}}$ ) (Figure 1, E), MIL-101(Ti ${ }^{\mathrm{III}}$ )-BPDC (Figure 1, F) and MIL-100(Ti ${ }^{\mathrm{III}}$ )-TATB (Figure 1, G) $\left(\mathrm{BPDC}=4,4^{\prime}\right.$-biphenyldicarboxylate; TATB = 4,4',4' '-[1,3,5]triazine-2,4,6-triyltris-benzoate).

Interestingly, the MOFs obtained by this electrochemical-mediated approach were compared with products obtained solvothermally from commercial $\mathrm{TiCl}_{3}$ in the absence of $\mathrm{NBu}_{4} \mathrm{PF}_{6}$. In addition to a higher crystallinity and porosity, X-ray photoelectron spectroscopy analysis indicated that the electrochemically obtained MOFs contain $\mathrm{F}^{-}$as charge counterbalancing anions, whereas the solvothermally obtained ones seemed to contain $\mathrm{Cl}^{-}$. This latter observation, based on results of a surface analysis, is in disagreement with the report of Mason et al. ${ }^{27}$ who used a very similar procedure to obtain their MIL-101( $\left.\mathrm{Ti}^{\mathrm{III}}\right)$ with an ethoxide charge balancing anion. To the best of our knowledge, up to now, there have been no reports on $\mathrm{Ti}^{\mathrm{III}}$-MOFs that contain functionalities within their linkers. Adding such functionalities could not only have an important impact on the properties of the resulting MOFs for various applications in fields such as gas adsorption or catalysis, ${ }^{37,38}$ but it could also open the door for further post-functionalization of the materials to 
modify their properties. ${ }^{39,40,41}$ For those reasons, we have decided to focus on the development of $\mathrm{NH}_{2}-\mathrm{MIL}-101\left(\mathrm{Ti}^{\mathrm{III}}\right.$ ) (Figure 1, H.), a derivative of MIL-101( $\mathrm{Ti}^{\mathrm{III}}$ ) with amine functions on its linkers.

The MOF described in this work contains a small amount of aluminum, from the titanium (III) precursor used for the synthesis, and is thus a bimetallic MOF. Interestingly, only one previous literature report concerns the synthesis of Ti-based bimetallic MOFs with the MTN (MIL-100 (Figure 1, E.) or PCN-333 topology (another name for MIL-100-TATB, Figure 1, G.)), containing scandium as a second metal. ${ }^{42}$ However, the previously reported strategy relied on the exchange of the very expensive $\mathrm{Sc}^{3+}$ in the pre-synthesized monometallic Sc-based MOFs by $\mathrm{Ti}^{3+}$. Our bimetallic $\mathrm{NH}_{2}-\mathrm{MIL}-101\left(\mathrm{Ti}^{\mathrm{III}}, \mathrm{Al}\right) \mathrm{MOF}$ is obtained by a much cheaper and facile, one-pot synthetic strategy. 

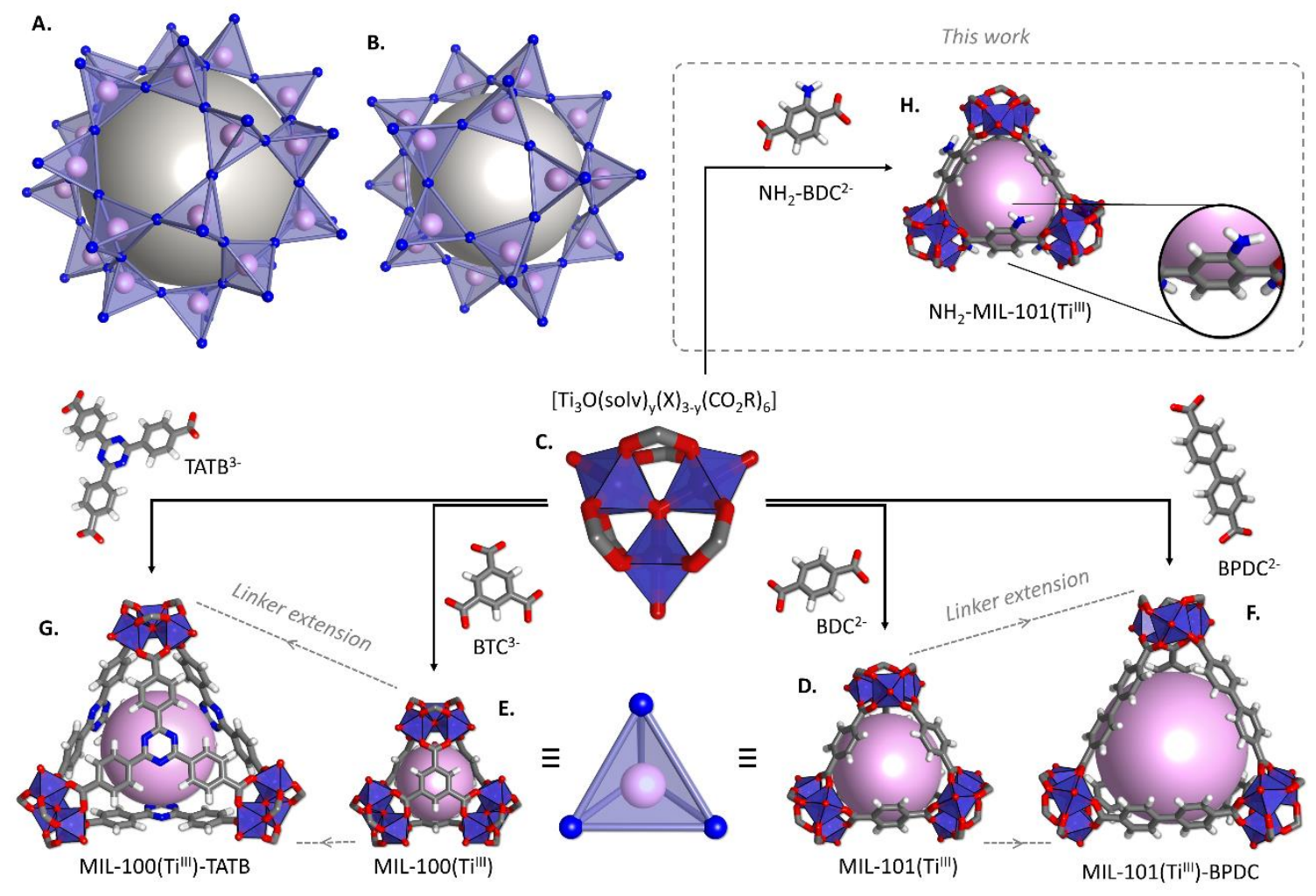

$\left[\mathrm{Ti}_{3} \mathrm{O}(\text { solv })_{\mathrm{y}}(\mathrm{X})_{3-\mathrm{y}}\left(\mathrm{CO}_{2} \mathrm{R}\right)_{6}\right]$

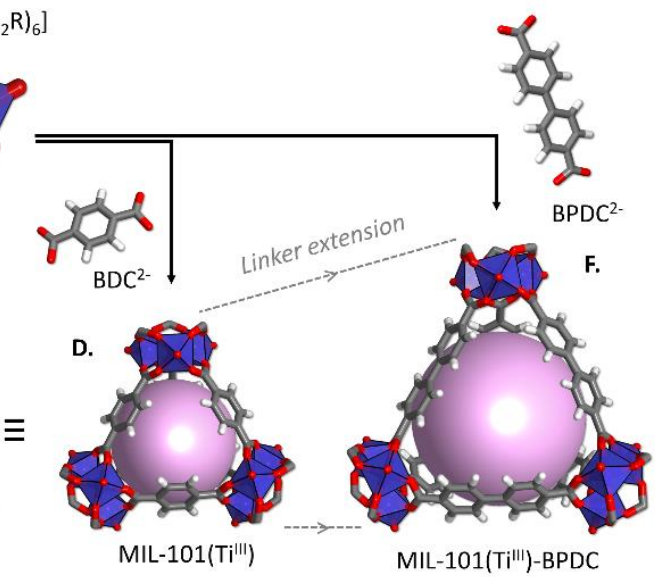

Figure 1. (A. and B.) Assembly of the supertetrahedra into large and small mesoporous cages forming MOFs with MTN topology. The structure of microporous supertetraedra in previously described Ti ${ }^{\text {III- }}$ based MOFs with MTN topology containing the $\left(\mathbf{C}_{\text {. }) ~}\left[\mathrm{Ti}_{3} \mathrm{O}(\mathrm{solv})_{\mathrm{y}}(\mathrm{X})_{3-\mathrm{y}}\left(\mathrm{CO}_{2} \mathrm{R}\right)_{6}\right]\right.$ cluster based on (D.) $\mathrm{BDC}^{2-}$, (E.) $\mathrm{BTC}^{3-}$ linkers or their extended versions, (F.) $\mathrm{BPDC}^{2-}$ and (G.) $\mathrm{TATB}^{3-}$. (H.) The supertetrahedron of the new MOF described in this work, $\mathrm{NH}_{2}-\mathrm{MIL}-101\left(\mathrm{Ti}^{\mathrm{III}}\right)$ is represented in the inset, with an enlargement around the amine function. Color code: deep blue $=\mathrm{Ti}$; red $=\mathrm{O}$, grey $=\mathrm{C}$; marine blue $=\mathrm{N}$; white $=\mathrm{H}$; large pink spheres $=$ micropores formed by the supertetrahedra . 


\section{Materials and methods}

\section{Chemicals and syntheses}

$\left(\mathrm{TiCl}_{3}\right)_{3} \mathrm{AlCl}_{3}\left(76.0-78.5 \% \mathrm{TiCl}_{3}\right)$ and acetyl chloride $(98 \%)$ were purchased from Alfa Aesar. Dry toluene $\left(99.85 \%\right.$, Extra dry, AcroSeal $\left.{ }^{\circledR}\right)$, 4-bromoacetophenone (98\%), potassium pyrosulfate (98 $\%$ ), $n$-BuLi (1.6 M in hexanes) and 2,4,6-trimethylaniline (97\%) were purchased from Acros Organics. Dry THF ( $\geq 99.9 \%$, with 250 ppm BHT as inhibitor), aluminum chloride (99.9\%) and 2aminoterephthalic acid (99\%) were purchased from Sigma Aldrich. DMF (HiPerSolv, CHROMANORM $^{\circledR}$ ), DCM (HiPerSolv, CHROMANORM®), sulfuric acid (96\%), chloroform (HiPerSolv, CHROMANORM ${ }^{\circledR}$ ), concentrated hydrochloric acid (37\%), glacial acetic acid (ACS reagent grade), ethanol (technical grade) were purchased from VWR. The used acetone was of technical grade. Triethylamine $\left(99.7 \%\right.$ ) was purchased from Fisher Chemicals. $\mathrm{CDCl}_{3}, \mathrm{NaOD}$ $\left(40 \%\right.$ w/w in $\left.\mathrm{D}_{2} \mathrm{O}, \geq 99.00 \%\right)$ and $\mathrm{D}_{2} \mathrm{O}$ were purchased from Eurisotop. Carbon dioxide (Alphagaz 1) was purchased from Air Liquide. Potassium permanganate crystals were purchased from J. T. Baker Chemicals N.V. (Holland).

Synthesis of $\mathrm{Ti}_{3-x} A l_{x} \mathrm{Cl}_{3}(\mathrm{THF})_{3}$

$\mathrm{TiCl}_{3}(\mathrm{THF})_{3}$ was synthesized from $\left(\mathrm{TiCl}_{3}\right)_{3} \mathrm{AlCl}_{3}$ according to a reported procedure. ${ }^{43}$ In brief: in a glovebox, $20 \mathrm{~g}$ of $\left(\mathrm{TiCl}_{3}\right)_{3} \mathrm{AlCl}_{3}$ was loaded in a $250 \mathrm{~mL}$ custom-made Schlenk flask equipped with a glass-frit filter (see Fig. S1) containing a magnetic stirring bar and the flask was closed with a rubber septum. Outside the glovebox, maintaining the flask under argon atmosphere (using a Schlenk line), $10 \mathrm{~mL}$ of dry toluene was added to the flask, which was subsequently cooled down to $-63^{\circ} \mathrm{C}$ using a $\mathrm{CHCl}_{3} /$ liquid nitrogen mixture. $200 \mathrm{~mL}$ of dry $\mathrm{THF}$ was then added to the mixture, which was subsequently stirred at room temperature for one hour, allowing the formation of a pale blue solid. The product was then isolated by filtration under vacuum and the solid was washed several times with degassed (by argon bubbling) hexane and dried under vacuum to yield pale blue crystalline $\mathrm{TiCl}_{3}(\mathrm{THF})_{3}$. The analysis of the obtained solid by ICP-OES revealed some residual aluminum, the compound can be formulated as $\mathrm{Ti}_{0.93} \mathrm{Al}_{0.07} \mathrm{Cl}_{3}(\mathrm{THF})_{3}$ (see supporting info).

Synthesis of $\mathrm{NH}_{2}-\mathrm{MIL}-101\left(\mathrm{Ti}^{\mathrm{III}}, \mathrm{Al}\right)$

A yellow solution containing 0.126 (or 0.63 ) g of 2-aminoterephthalic acid in 15 (or 75 ) $\mathrm{mL}$ of DMF was introduced in a $500 \mathrm{~mL}$ GL32 glass bottle equipped with a magnetic stirring bar. A B29/32 rubber septum from which the collar had been previously cut off (see Fig. S2, A.) was then 
used to close the bottle and the solution was degassed by passing argon through it with the help of a long needle. Separately, a dark blue solution containing 0.556 (or 2.78) g of $\mathrm{Ti}_{0.93} \mathrm{Al}_{0.07} \mathrm{Cl}_{3}(\mathrm{THF})_{3}$ (weighed in a glovebox, see preparation above) in 15 (or 75) $\mathrm{mL}$ of degassed (argon bubbling) DMF was prepared using Schlenk techniques. This $\mathrm{Ti}^{\mathrm{III}}$-containing solution was then added to the linker solution via cannula under stirring, yielding a dark blue solution. A heat resistant $\left(180^{\circ} \mathrm{C}\right)$ screw cap with flat interior (see Fig. S2, A.) was then fitted on the glass bottle to secure the rubber septum. The glass bottle was then introduced in a preheated oven at $130^{\circ} \mathrm{C}$ to allow crystallization of the MOF during 18h (without stirring). The solution was then allowed to cool down to room temperature and the septum was removed carefully (Attention! Internal pressure is possible at this stage and the rubber septum might pop off the bottle! It is recommended to insert a needle into the septum just after removal of the screw cap in order to remove excess pressure). The solution was then filtered over a nylon membrane under a continuous flux of argon (see experimental setup in Fig. S2, B.), to separate the brown MOF from the dark blue solution. The product was then washed several times with degassed (by argon bubbling) DMF and acetone until a clear filtrate was obtained. Special care was taken at this stage to never allow the product to dry completely or passing air through it (oxidation by air resulting in a color change of the MOF from chocolate to yellow). After a final washing with acetone, the still slightly wet product (the solvent in the pores allows to exclude oxygen) was quickly transferred to a round bottom flask with a large (B29/32) neck that was fitted to a glass stopcock and the product was then put under vacuum. This last step must be performed quickly as the product may not dry in the air, otherwise quick oxidation and degradation of the MOF occurs. The MOF was then dried under vacuum and heated at $130^{\circ} \mathrm{C}$ for about 10 min to give $\mathrm{NH}_{2}$-MIL-101( $\mathrm{Ti}^{\mathrm{III}}, \mathrm{Al}$ ) as a dark brown (chocolate) powder that can be stored in an argon-filled glovebox. Alternatively, the filtration step might be performed in a dedicated glovebox, but as DMF dissolves most types of plastic (and can therefore cause damage to the transparent windows of gloveboxes) this is not recommended and is at the risk of the experimentalist.

\section{Activation of $\mathrm{NH}_{2}-\mathrm{MIL}-101\left(\mathrm{Ti}^{\mathrm{III}}\right.$, Al) in boiling DCM}

Inside an argon-filled glovebox, about 1 gram of as-synthesized $\mathrm{NH}_{2}-\mathrm{MIL}-101\left(\mathrm{Ti}^{\mathrm{III}}, \mathrm{Al}\right)$ was loaded in a large glass $100 \mathrm{~mL}$ test tube with a ground glass joint, together with a magnetic stirring bar. The glass tube was then closed with a rubber septum and removed from the glovebox. On a Schlenk line, about $40 \mathrm{~mL}$ of $\mathrm{CH}_{2} \mathrm{Cl}_{2}$ (DCM) degassed by Ar bubbling was added to the solid. The 
tube was immerged in a beaker containing hot water $\left(\sim 50^{\circ} \mathrm{C}\right)$ and stirring was started. The DCM was allowed to boil during 5 to $10 \mathrm{~min}$, after which the beaker with hot water was removed and stirring was stopped to allow decantation of the solid. The supernatant was then removed via cannula. Fresh degassed DCM was then added for a second washing. This procedure was repeated five times. After the fifth washing and removal of DCM, the product was dried under vacuum and then transferred to a glovebox for storage prior to further analyses.

Synthesis of MIL-101(Al)-NH

Crystallographically pure MIL-101(Al)- $\mathrm{NH}_{2}$ was obtained through a slightly modified procedure taken from the literature. ${ }^{44}$ In brief, a solution of $0.63 \mathrm{~g} 2$-aminoterephthalic acid in $75 \mathrm{~mL}$ of DMF was heated to $130^{\circ} \mathrm{C}$ in a $500 \mathrm{~mL}$ round-bottom flask equipped with a magnetic stirrer. Then, a clear solution containing $1.81 \mathrm{~g}$ of previously dissolved aluminum chloride hexahydrate in $75 \mathrm{~mL}$ of DMF (slow dissolution) was added dropwise with the help of an addition funnel over a period of one hour. The mixture was then stirred further at $130^{\circ} \mathrm{C}$ for $14 \mathrm{~h}$. The yellow precipitate was recovered through centrifugation and washed several times with DMF and acetone until a clear supernatant was obtained. The MOF was recovered as a yellow powder upon drying in a vacuum oven at $60^{\circ} \mathrm{C}$ for about 1 hour. To avoid any degradation from moisture, the MOF was stored in an argon-filled glovebox.

\section{Synthesis of complementary linkers}

1,3,5-tris(carboxyphenyl)benzene was synthesized according to a previously described procedure. $^{45}$ In brief, $3.04 \mathrm{~g}$ of 4-bromoacetophenone and $4.09 \mathrm{~g}$ of potassium pyrosulfate were finely ground with a mortar and pestle and were subsequently introduced in a $100 \mathrm{~mL}$ round-bottom flask equipped with a magnetic stirring bar. $0.2 \mathrm{~mL}$ of concentrated sulfuric acid (96\%) was then added dropwise under stirring. The reaction mixture was heated at $180{ }^{\circ} \mathrm{C}$ during $16 \mathrm{~h}$ using an oil bath. After cooling down the reaction mixture to room temperature, $25 \mathrm{~mL}$ of ethanol was added and the mixture refluxed for two hours. The solid was then filtered off and washed two times with ethanol. The solid was subsequently introduced in a $100 \mathrm{~mL}$ round bottom flask, and refluxed in water for one hour, followed by filtration and two washings with water. The product was finally recrystallized in chloroform to yield the 1,3,5-tris(4-carboxyphenyl)benzene intermediate. 0.84 of the obtained 1,3,5-tris(4-carboxyphenyl)benzene were then introduced in a dry three-neck flask equipped with an entrance and exit for $\mathrm{CO}_{2}$ and a rubber septum. $100 \mathrm{~mL}$ of dry THF were added 
to the reaction medium, which was cooled down to $-78{ }^{\circ} \mathrm{C}$ (acetone/dry ice bath) under stirring. $2.35 \mathrm{~mL}$ of a $1.6 \mathrm{M}$ solution of $n$-BuLi in hexanes were then added dropwise through the rubber septum and reacted further for 5 minutes. Gaseous $\mathrm{CO}_{2}$ was then bubbled through the reaction medium to precipitate the product and the reaction was quenched by addition of $20 \mathrm{~mL}$ of a $50 / 50$ mixture of acetic acid and water. Concentrated (37\%) hydrochloric acid was added slowly until no more product precipitated. The obtained powder was recrystallized in hot acetic acid and dried at $120{ }^{\circ} \mathrm{C}$ under vacuum. The final linker was obtained in $50 \%$ yield. ${ }^{1} \mathrm{H}-\mathrm{NMR}\left(\mathrm{CDCl}_{3}, 300 \mathrm{MHz}\right.$, $\delta): 7.69$ ppm, s, 3H; 7.63-7.52 ppm, m, $12 \mathrm{H}$.

$N$-mesitylacetamide was obtained through a previously described procedure. ${ }^{46} \mathrm{In}$ brief, $10.5 \mathrm{ml}$ of 2,4,6-trimethylaniline were introduced under argon in a flame-dried $500 \mathrm{ml}$ round-bottom flask equipped with a Teflon stir bar and a rubber septum. $100 \mathrm{ml} \mathrm{CH}_{2} \mathrm{Cl}_{2}$ was added to the flask and the mixture was cooled down to $0^{\circ} \mathrm{C}$ (ice bath). $5.6 \mathrm{ml}$ acetyl chloride was added dropwise by syringe, followed by $11 \mathrm{ml}$ triethylamine. After $2 \mathrm{~h}$ of reaction, the mixture was filtered. The solid was then suspended in water and stirred for $30 \mathrm{~min}$. The solid was then collected by filtration and was dried under vacuum. 2-aminobenzene-1,3,5-tricarboxylic acid (2-aminotrimesic acid, $\mathrm{H}_{3} \mathrm{BTCNH}_{2}$ ) was also obtained through a previously described procedure. ${ }^{46} \mathrm{In}$ brief, $5 \mathrm{~g}$ of the obtained $\mathrm{N}$ mesitylacetamide and $165 \mathrm{ml}$ of water were introduced in a $500 \mathrm{ml}$ round bottom flask, followed by the portion wise addition of $0.55 \mathrm{~g}$ sodium hydroxide. Then, $34 \mathrm{~g}$ of $\mathrm{KMnO}_{4}$ were added in portions ( $\sim 5$ portions) over $\sim 2 \mathrm{~h}$ under vigorous stirring. The flask was then equipped with a condenser and the solution was heated under stirring at $85^{\circ} \mathrm{C}$ for $72 \mathrm{~h}$. The reaction mixture was then filtered through filter paper and the $\mathrm{MnO}_{2}$ was rinsed with $\sim 200 \mathrm{ml}$ of hot water. The obtained filtrate was acidified with $40 \mathrm{ml}$ of $\mathrm{HCl}$ and the mixture was refluxed overnight $\left(100^{\circ} \mathrm{C}\right)$. The obtained white solid was then filtered and rinsed with ice-cold water. ${ }^{1} \mathrm{H} \mathrm{NMR}\left(\mathrm{CDCl}_{3}, 300 \mathrm{MHz}\right.$,

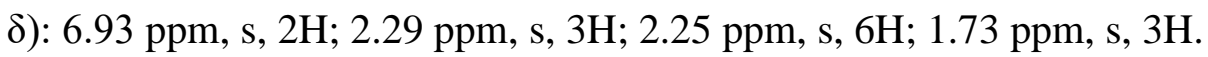

\section{Analytical}

Inductively-coupled plasma optical emission spectroscopy (ICP-OES) and chlorine analyses (Schöniger flask method) were performed by Medac Ltd.

PXRD patterns were measured in glass capillaries $(0.7 \mathrm{~mm}$ diameter, Hilgenberg $\mathrm{GmbH})$ that were filled with the samples in a glovebox and sealed with grease. Before analysis, the capillaries were 
cut and instantly placed into molten wax on goniometric heads and the measurements were performed immediately after preparation to avoid air from entering. The analysis was performed using a MAR345 image plate detector and an Incoatec Microfocus Source HIGHBRILLIANCE $\left(\mathrm{I} \mu \mathrm{S}^{\mathrm{HIGHBRILLIANCE}}\right) \mathrm{Mo}$ ELM47 operating at $50 \mathrm{kV}$ and $1000 \mu \mathrm{A}$. The samples were exposed to $\mathrm{X}$ rays for 5 minutes during which the capillary with the sample was rotated by $180^{\circ}$. Diffraction data was integrated by the Fit2D software (using data from a $0.1 \mathrm{~mm}$ diameter capillary filled with $\mathrm{LaB}_{6}$ as calibrant). Variable-temperature PXRD (VT-PXRD) was performed by heating the samplecontaining capillary with a Leister LE MINI SENSOR KIT hot air blower (Leister Technologies Benelux B.V.). The air blower was calibrated by a thermocouple housed in a capillary; the determined error on sample temperature is $\pm 5^{\circ} \mathrm{C}$. Alternatively, PXRD measurements were collected on a STOE STADI P Combi diffractometer using $\mathrm{CuK}_{\alpha 1}$ radiation $(40 \mathrm{kV}, 40 \mathrm{~mA})$ (graphite primary monochromator). The diffracted beam was recorded on a DECTRIS MYTHEN $1 \mathrm{~K}$ strip detector. Samples were loaded in $0.7 \mathrm{~mm}$ diameter capillaries, aligned to the geometric center of the diffractometer and measured in transmission, with independent 2-theta movement.

FTIR spectra were measured with a Bruker Alpha spectrometer equipped with a Platinum ATR sample holder (diamond crystal, single bounce) housed in an argon-filled glovebox.

Nitrogen physisorption measurements were performed on an ASAP2020 device from Micromeritics at $77 \mathrm{~K}$. The sample tube was filled inside a glovebox to avoid degradation.

TGA measurements were performed using a Netszch STA 449 F3 TGA/DSC equipped with a stainless steel oven hosted in an argon-filled glovebox. Conventional TGA was run with a heating speed of $10 \mathrm{~K} / \mathrm{min}$ under argon atmosphere until $500^{\circ} \mathrm{C}$, followed by air/argon (reactive/protective gas) from $500^{\circ} \mathrm{C}$ to $900^{\circ} \mathrm{C}$.

${ }^{1} \mathrm{H}-\mathrm{NMR}$ spectra were recorded at room temperature (296 K) on a Bruker Avance 500 spectrometer operating at $500.13 \mathrm{MHz}$ using a BBFO $\left\{{ }^{1} \mathrm{H}, \mathrm{X}\right\}$ probehead equipped with a $z$-gradient coil. The measurements were performed using the standard Bruker zg pulse program. Acquisition time was fixed to $1.6 \mathrm{~s}$, number of scans to 16 and relaxation delay was $30 \mathrm{~s}$. About $5 \mathrm{mg}$ of activated MOF were weighed in a glovebox and introduced in a $4 \mathrm{~mL}$ screw-capped vial. Outside the glovebox, $0.2 \mathrm{~mL}$ of concentrated $\mathrm{NaOD}$ was added to the sample, followed by $1.0 \mathrm{~mL}$ of $\mathrm{D}_{2} \mathrm{O}$ (allowing air to enter the vial to oxidize the paramagnetic $\mathrm{Ti}^{\mathrm{III}}$ to $\mathrm{Ti}^{\mathrm{IV}}$ ). The suspension was then shaken, heated with a heat gun and sonicated until a white suspension, formed by dissolved organic species and 
sodium salts together with solid titanium oxides/hydroxides, was obtained. The suspension was filtered using a PTFE syringe filter $(0.45 \mu \mathrm{m})$ to obtain a clear solution. $0.6 \mathrm{~mL}$ of the obtained solution was used for NMR determination. Reference solutions of "digested" formic acid and DMF (spectra not shown) were obtained by the same procedure.

Hydrogen sorption isotherms were measured on a Micromeritics ASAP2020 device, according to Application Note 136 of the manufacturer (www.micromeritics.com). A degassing temperature different from that in the application note $\left(100^{\circ} \mathrm{C}\right.$ instead of $\left.300^{\circ} \mathrm{C}\right)$ was used to avoid sample degradation. Measurements were performed at $77 \mathrm{~K}$ in the pressure range between 0 and 620 mbar with Alphagaz 1 grade hydrogen from Air Liquide. 


\section{Results and discussion}

\section{Synthesis of $\mathrm{NH}_{2}-\mathrm{MIL}-101\left(\mathrm{Ti}^{I I I}\right)$ and attempts with other linkers}

Most $\mathrm{Ti}^{\mathrm{III}}$ complexes are quite expensive precursors and therefore unsuitable for synthesizing large amounts of $\mathrm{Ti}^{\mathrm{III}}$-based MOFs. Therefore, the cheap commercially available $\left(\mathrm{TiCl}_{3}\right)_{3} \mathrm{AlCl}_{3}$ was investigated as metal source for synthesizing $\mathrm{Ti}^{\mathrm{III}}$-containing $\mathrm{NH}_{2}-\mathrm{MIL}-101(\mathrm{M}) \mathrm{MOFs}(\mathrm{M}=\mathrm{Ti}$ and/or Al). The synthesis was performed by making two solutions of each of the precursors (metal and linker) in DMF as only solvent, which easily dissolves all the reactants. Those were then mixed together under argon and the resulting solution was subsequently heated in a closed glass vial at $130^{\circ} \mathrm{C}$, well below the boiling point of DMF. Care was taken to do so by excluding air from entering (see experimental part and Fig. S2), as Ti ${ }^{\mathrm{III}}$ easily oxidizes. Unfortunately, attempts when directly using the bimetallic $\left(\mathrm{TiCl}_{3}\right)_{3} \mathrm{AlCl}_{3}$ precursor resulted in a very fine powder that was unrecoverable through filtration, and readily oxidized in air. In the same reaction conditions, using pure $\mathrm{AlCl}_{3}$, we obtained an amorphous material, as revealed by powder X-ray diffraction (PXRD) (not shown), that could only be isolated by centrifugation. As we expected that $\mathrm{Al}$ was responsible of the small particle size obtained when using $\left(\mathrm{TiCl}_{3}\right)_{3} \mathrm{AlCl}_{3}$, we reacted this bimetallic precursor with $\mathrm{THF}$ to form a light blue solid, likely $\mathrm{TiCl}_{3}(\mathrm{THF})_{3}$, which is insoluble in alkanes, allowing to easily eliminate the soluble $\mathrm{AlCl}_{3}$ through simple filtration, according to [43]. Although the obtained $\mathrm{TiCl}_{3}(\mathrm{THF})_{3}$ still contained some residual aluminum, as determined by ICP analysis (the obtained complex was determined as being $\mathrm{Ti}_{0.93} \mathrm{Al}_{0.07} \mathrm{Cl}_{3}(\mathrm{THF})_{3}$, see Table S3), we were able to obtain crystallographically pure $\mathrm{Ti}^{\mathrm{III}}$-containing $\mathrm{NH}_{2}-\mathrm{MIL}-101$ from this precursor (Fig. S3 and Figure 2). We performed this successful synthesis twice, in a reproducible manner. The product's crystal structure has been assessed by PXRD, showing that it is isostructural to other MIL-101 MOFs (Figure 3 and Fig. S3), and its infrared spectrum showed the characteristic features of $\mathrm{NH}_{2}$-MIL-101 frameworks, as well as the absence of reactants in the obtained MOF (Fig. S4). ICPOES analysis (Table S6) revealed that the obtained MOF is bimetallic in nature, having a Ti/Al ratio of $85 / 15$, which indicates that $\mathrm{Al}$ is preferentially incorporated in the framework compared to $\mathrm{Ti}^{\mathrm{III}}$, as the precursor contains a 93/7 Ti/Al ratio. This is in accordance with the fact that the filtrate after synthesis was blue in color, indicating that some $\mathrm{Ti}^{\mathrm{iII}}$ used for the synthesis was not incorporated in the MOF. The obtained MOF is thus named $\mathrm{NH}_{2}-\mathrm{MIL}-101$ (Ti $\left.{ }^{\mathrm{III}}, \mathrm{Al}\right)$ further in this work. 
It is noteworthy that using terephthalic acid instead of 4-aminoterephthalic acid as linker source resulted in a mixture of crystalline phases including MIL-101(Ti ${ }^{\mathrm{III}}$ ) (Fig. S5), evidencing that the presence of an amine function is essential for selectively obtaining the desired topology under the used conditions. Interestingly, one of the phases in this latter attempt seems isostructural to MOF-235 (Fig. S5, A.), which has been reported only with a limited number of metals, including $\mathrm{Fe}^{47}$ and $\mathrm{Al}$ for which it has been described only with an amine function on the linker. ${ }^{48}$ In addition, the way of performing the mixing is of importance for the outcome of the reaction. This was demonstrated in the case of the reaction with $\mathrm{AlCl}_{3}$ as precursor, for which pure $\mathrm{NH}_{2}-\mathrm{MIL}-101(\mathrm{Al})$ could be obtained by slowly adding a solution of 4-aminoterephthalic acid to a preheated solution of $\mathrm{AlCl}_{3}$ (Fig. S6), but not by heating a cold solution of both reactants. This is intrinsically linked to the formation mechanism of $\mathrm{NH}_{2}$-MIL-101(Al), which is discussed in one of our review articles. ${ }^{49}$ The slow addition of the aluminum chloride solution to the preheated solvent mixture, which is a small but important modification compared to the previously described syntheses, even allowed obtaining an $\mathrm{NH}_{2}$-MIL-101(Al) MOF with the highest surface area yet described for this $\operatorname{MOF}\left(\mathrm{S}_{\mathrm{BET}}=3440 \mathrm{~m}^{2} / \mathrm{g}\right.$, Table 1 and Table $\left.\mathrm{S} 2\right)$. Amorphous materials were also obtained when using tritopic linker precursors such as trimesic acid $\left(\mathrm{H}_{3} \mathrm{BTC}\right)$ or 1,3,5-tris(carboxyphenyl)benzene $\left(\mathrm{H}_{3} \mathrm{BTB}\right)$, or in the presence of water (Fig. S5, B. and C.). Interestingly, the use of 2-aminotrimesic acid $\left(\mathrm{H}_{3} \mathrm{BTCNH} \mathrm{H}_{2}\right)$ as trimeric linker allowed obtaining a MOF with the MTN topology (MIL-100), although the important broadening of the peaks in the PXRD pattern could indicate the presence of a large number of defects or small crystallites (Fig. S5, D.). This last synthesis further indicates that the presence of an amine function seems to facilitate the synthesis of MOFs with the MTN topology using $\mathrm{TiCl}_{3}(\mathrm{THF})_{3}$ as precursor. However, owing to the difficulty of analyzing defects, ${ }^{50}$ this last MOF has not been analyzed further, due to the extreme sensitivity of the product towards air. All the tested synthetic parameters and outcome of the reactions are given in Table S1. 


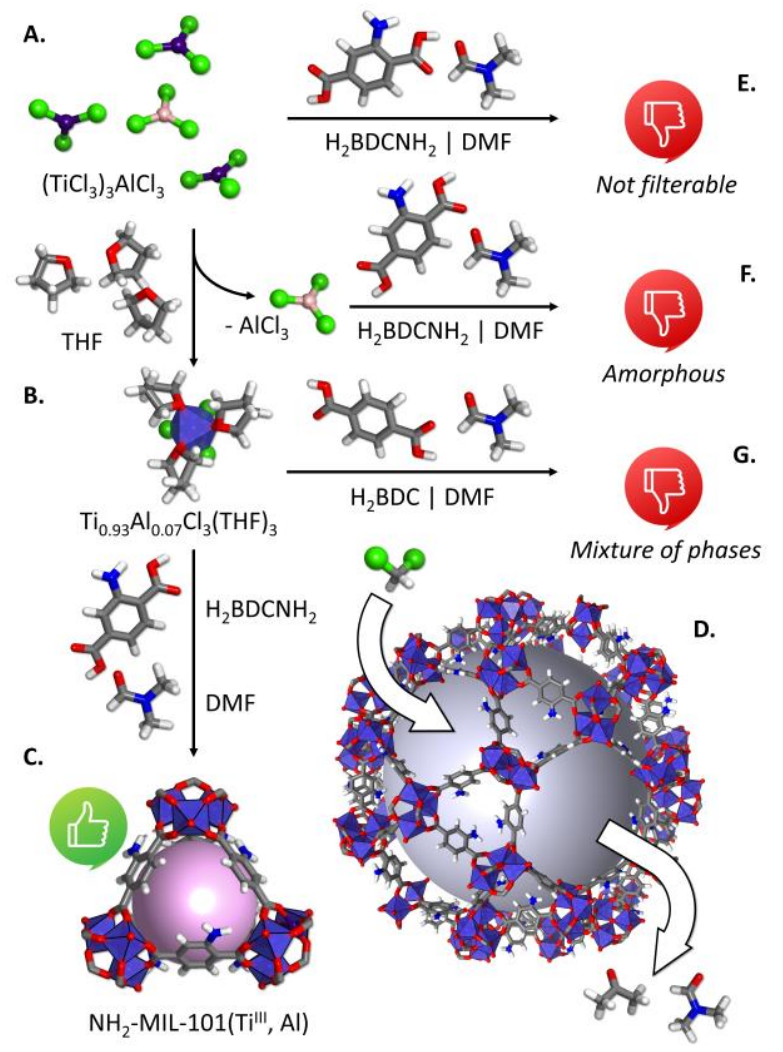

Figure 2. Conversion of (A.) $\left(\mathrm{TiCl}_{3}\right)_{3} \mathrm{AlCl}_{3}$ into (B.) $\mathrm{Ti}_{0.93} \mathrm{Al}_{0.07} \mathrm{Cl}_{3}(\mathrm{THF})_{3}$ complex and its reaction with 4-aminoterephthalic acid in DMF at $130^{\circ} \mathrm{C}$ to yield (C.) $\mathrm{NH}_{2}-\mathrm{MIL}-101$ (Ti ${ }^{\mathrm{III}}, \mathrm{Al}$ ), from which (D.) physisorbed DMF and acetone was exchanged for DCM. Attempts to obtain similar MOFs in DMF at $130^{\circ} \mathrm{C}$ by either engaging $\left(\mathbf{E}\right.$.) $\left(\mathrm{TiCl}_{3}\right)_{3} \mathrm{AlCl}_{3}$ or $(\mathbf{F}$. $) \mathrm{AlCl}_{3}$ as metal sources or $(\mathbf{G}$.) non-functionalized terephthalic acid as linker source did not yield the desired material.

\section{Thermal stability and porosity}

The thermal stability of $\mathrm{NH}_{2}-\mathrm{MIL}-101\left(\mathrm{Ti}^{\mathrm{III}}, \mathrm{Al}\right)$ was evaluated by means of thermogravimetric analysis by heating the sample at $10 \mathrm{~K} \cdot \mathrm{min}^{-1}$ under argon from room temperature to $500^{\circ} \mathrm{C}$, and under air from $500^{\circ} \mathrm{C}$ to $900^{\circ} \mathrm{C}$ to be able to calculate theoretical weight losses after calcination. PXRD analysis of the oxidation product was performed to confirm that $\mathrm{TiO}_{2}$, as a mixture of essentially rutile with small amounts of anatase (see Fig. S7) was the final combustion residue, together with some $\mathrm{Al}_{2} \mathrm{O}_{3}$, which is not visible on the PXRD pattern either because of the small proportion or tiny crystallite size in the combustion residue or because it is obtained as an amorphous phase or due to the microabsorption effect. The theoretical $\mathrm{TiO}_{2} / \mathrm{Al}_{2} \mathrm{O}_{3}$ ratio should be 92/8, according to the ICP-determined proportion of both metals in the MOF ( $\mathrm{Ti} / \mathrm{Al}=2.54 / 0.46$, see Table S6). The TGA results (Figure 3 A., inset) highlight a constant weight loss over the 
complete temperature range under argon with no well-defined plateau, indicating that removal of solvents is overlapping with framework decomposition.

A.

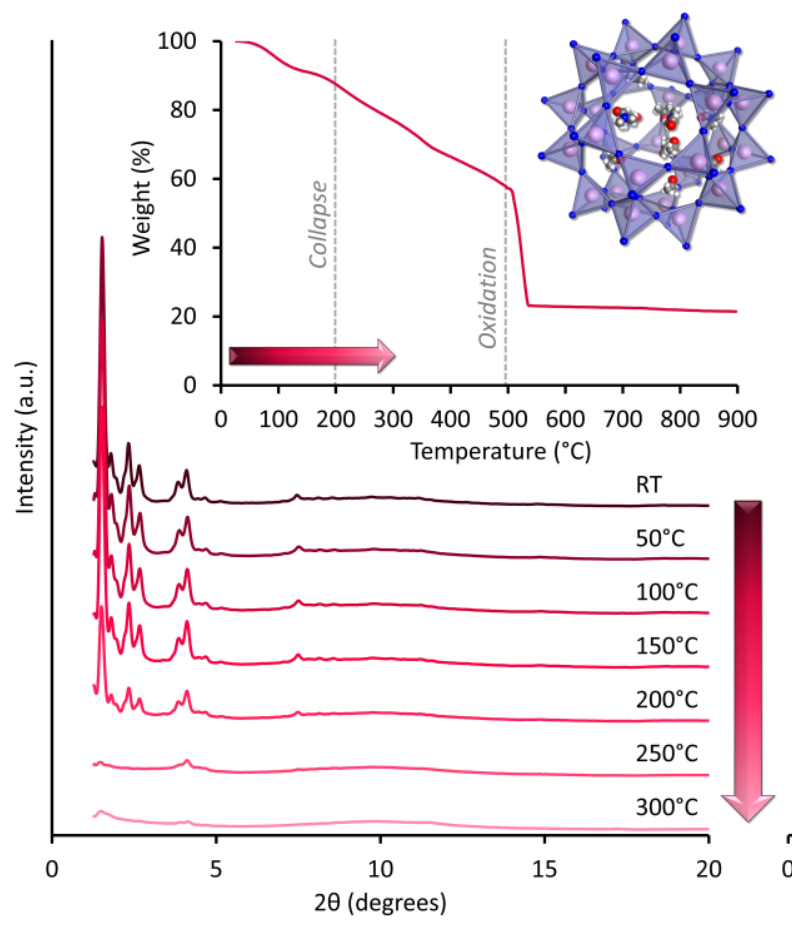

B.

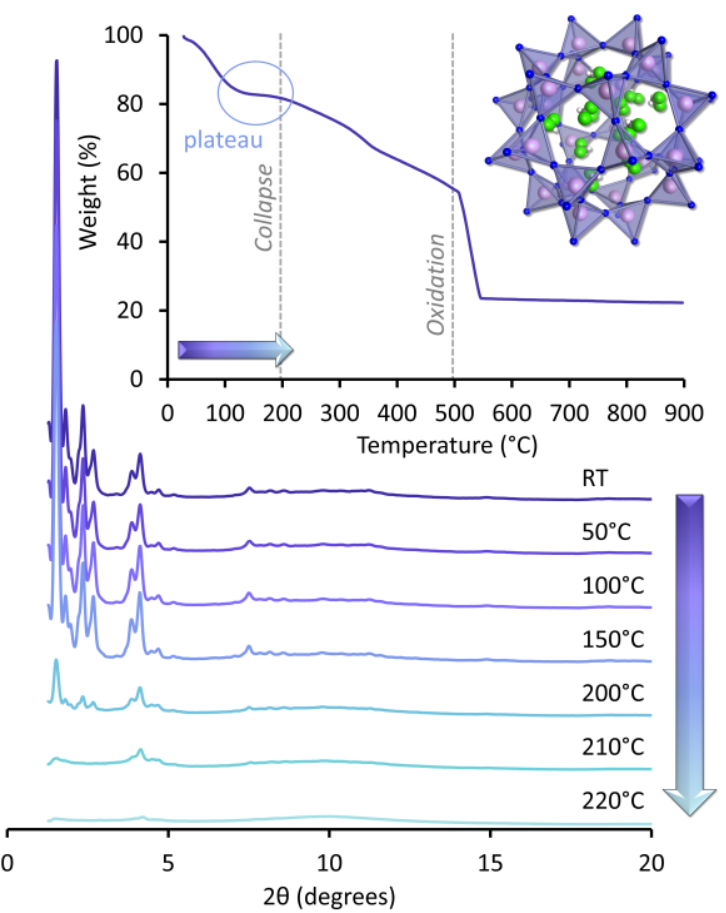

Figure 3. Variable-temperature PXRD patterns and (insets) thermal gravimetric analysis of (A.) assynthesized and (B.) DCM-exchanged $\mathrm{NH}_{2}-\mathrm{MIL}-101$ ( $\left.\mathrm{Ti}^{\mathrm{III}}, \mathrm{Al}\right)$. TGA were recorded with a heating speed of $10 \mathrm{~K} \cdot \mathrm{min}^{-1}$ under argon until $500^{\circ} \mathrm{C}$, followed by oxidation under air from $500^{\circ} \mathrm{C}$ to $900^{\circ} \mathrm{C}$ (indicated by the "Oxidation" dashed line on the TGA curves). The schemes show the large mesopores of the MOF with (A.) acetone and DMF, and (B.) DCM molecules.

The MOF's decomposition temperature was therefore determined by in situ variable-temperature PXRD (VT-PXRD). From those experiments (Figure 3, A.), it appeared that the framework remains stable at least up to $150^{\circ} \mathrm{C}$, after which decomposition occurs, as shown by the intensity decrease of diffraction peaks from $200^{\circ} \mathrm{C}$, to yield an amorphous compound at higher temperatures. This quite low observed thermal stability, compared to that of some other $\mathrm{NH}_{2}-\mathrm{MIL}-101(\mathrm{M}) \mathrm{MOF}$ (see 
Table 1) could be due to the removal of residual solvents with high surface tension (i.e. residual DMF from the synthesis), which causes the framework to collapse. To remove any remaining DMF from the pores, the as-synthesized MOF was activated by refluxing five times in degassed boiling dichloromethane (DCM) (see experimental part), which is a solvent having a low surface tension. ${ }^{3}$ FTIR indicated that this procedure enabled successful exchange of the solvent molecules (Fig. S4). VT-PXRD was then performed on the DCM-activated MOF to evaluate changes in thermal stability (Figure 3, B.). However, the overall stability remained unchanged, as diffraction peaks started to vanish away at $200^{\circ} \mathrm{C}$, yielding an amorphous material at $210^{\circ} \mathrm{C}$. The observed thermal stability is lower than those previously observed for this type of materials with other metals ( 
Table 1), but is higher than the one of $\mathrm{NH}_{2}-\mathrm{MIL}-101(\mathrm{Al})$, that we determined experimentally to be around $150^{\circ} \mathrm{C}$ through VT-PXRD (Fig. S6). It should be noted that for $\mathrm{NH}_{2}-\mathrm{MIL}-101(\mathrm{Al})$ this decomposition temperature is much lower than $370-500^{\circ} \mathrm{C}$ that has been reported even in most recent literature (see Table 1) but whose determination was based on TGA data only. This indicates that TGA might overestimate the structural thermal stability of this type of MOFs, as this analysis only reflects the temperature at which the linker combustion occurs. ${ }^{16,52}$ Noteworthy, in both cases (as-synthesized and DCM-activated MOF), the color of the powder changed from chocolate to caramel after framework decomposition. The main change on the TGA curve of the DCM-activated MOF compared to the as-synthesized material is reflected by the plateau after solvent removal around $150^{\circ} \mathrm{C}$, indicating facilitated solvent removal from this sample and the stability of the sample with emptied pores until $200^{\circ} \mathrm{C}$. Furthermore, the intensities of the diffraction peaks of the activated material (Figure 3 and Fig. S8) are higher than for the as-synthesized one, indicating better crystallinity. Therefore, the DCM-activated sample was used for further experiments.

The accessible surface area of $\mathrm{NH}_{2}-\mathrm{MIL}-101\left(\mathrm{Ti}^{\mathrm{III}}, \mathrm{Al}\right)$ was probed by nitrogen physisorption at 77 $\mathrm{K}$ after activation of the sample under vacuum at $100^{\circ} \mathrm{C}$ and $150^{\circ} \mathrm{C}$ (Fig. S9). During thermal activation at those two temperatures, the sample lost $26.0 \%$ and $28.8 \%$ of its initial weight, respectively (for calculations, see Table S4). The results show that thermal activation at $100^{\circ} \mathrm{C}$ led to a BET surface area of $2024 \mathrm{~m}^{2} \cdot \mathrm{g}^{-1}$ ( $\left.\mathrm{S}_{\text {Langmuir: }} 2792 \mathrm{~m}^{2} \cdot \mathrm{g}^{-1}\right)$ whereas increasing the activation temperature to $150^{\circ} \mathrm{C}$ increased the BET surface area to $2146 \mathrm{~m}^{2} \cdot \mathrm{g}^{-1}\left(\mathrm{~S}_{\text {Langmuir: }} 2966 \mathrm{~m}^{2} \cdot \mathrm{g}^{-1}\right)$. The determined specific surface areas are in a similar range as those previously reported for similar MOFs based on other metals ( 
Table 1). FTIR analysis performed on the samples after nitrogen physisorption shows that the activation procedure efficiently removed DCM from the MOF's pores (Fig. S4). 
Table 1. Decomposition temperatures and surface areas of various reported MIL-101(M) and $\mathrm{NH}_{2}$-MIL-101(M) MOFs, together with those of $\mathrm{NH}_{2}$-MIL-101(Ti $\left.{ }^{\mathrm{III}}, \mathrm{Al}\right)$ described in this work.

\begin{tabular}{|c|c|c|c|c|c|}
\hline \multirow[t]{2}{*}{$\mathrm{MOF}$} & \multicolumn{2}{|c|}{$\begin{array}{c}\text { Decomposition } \\
\text { temperature } \\
\left({ }^{\circ} \mathrm{C}\right)\end{array}$} & \multicolumn{2}{|c|}{$\begin{array}{c}\text { Surface area } \\
\qquad\left(\mathrm{m}^{2} \cdot \mathrm{g}^{-1}\right)\end{array}$} & \multirow[t]{2}{*}{ Reference } \\
\hline & TGA & VT-PXRD & BET & Langmuir & \\
\hline \multirow[t]{2}{*}{ MIL-101(Cr) } & $\mathrm{n} / \mathrm{a}$ & $\mathrm{n} / \mathrm{a}$ & $2800-4230$ & $\mathrm{n} / \mathrm{a}$ & 12 \\
\hline & $\sim 350$ & $\mathrm{n} / \mathrm{a}$ & 2134 & $\mathrm{n} / \mathrm{a}$ & 53 \\
\hline $\mathrm{NH}_{2}-\mathrm{MIL}-101(\mathrm{Cr})$ & 250 & $\mathrm{n} / \mathrm{a}$ & 2070 & $\mathrm{n} / \mathrm{a}$ & 54 \\
\hline \multirow[t]{2}{*}{ MIL-101(Fe) } & $\mathrm{n} / \mathrm{a}$ & $\mathrm{n} / \mathrm{a}$ & 2123 & $\mathrm{n} / \mathrm{a}$ & 55 \\
\hline & $\mathrm{n} / \mathrm{a}$ & $\mathrm{n} / \mathrm{a}$ & 1420 & $\mathrm{n} / \mathrm{a}$ & 56 \\
\hline $\mathrm{NH}_{2}-\mathrm{MIL}-101(\mathrm{Fe})$ & $\mathrm{n} / \mathrm{a}$ & $\mathrm{n} / \mathrm{a}$ & 2572 & $\mathrm{n} / \mathrm{a}$ & 55 \\
\hline MIL-101(V) & 300 & $\mathrm{n} / \mathrm{a}$ & 3600 & 5700 & 19 \\
\hline MIL-101(Sc) & 450 & $\mathrm{n} / \mathrm{a}$ & $155-640$ & $\mathrm{n} / \mathrm{a}$ & 57 \\
\hline $\mathrm{NH}_{2}-\mathrm{MIL}-101(\mathrm{Sc})$ & $300^{*}$ & $\mathrm{n} / \mathrm{a}$ & $\mathrm{n} / \mathrm{a}^{*}$ & $\mathrm{n} / \mathrm{a}^{*}$ & 56 \\
\hline \multirow[t]{4}{*}{$\mathrm{NH}_{2}-\mathrm{MIL}-101(\mathrm{Al})$} & $\mathrm{n} / \mathrm{a}$ & $\sim 150$ & 3440 & 4799 & This work \\
\hline & $\mathrm{n} / \mathrm{a}$ & $\mathrm{n} / \mathrm{a}$ & 2074 & $\mathrm{n} / \mathrm{a}$ & 55 \\
\hline & $>377$ & $\mathrm{n} / \mathrm{a}$ & 2100 & $\mathrm{n} / \mathrm{a}$ & 16 \\
\hline & $>500$ & $\mathrm{n} / \mathrm{a}$ & 2530 & $\mathrm{n} / \mathrm{a}$ & 52 \\
\hline \multirow[t]{2}{*}{ MIL-101( $\left.\mathrm{Ti}^{\mathrm{III}}\right)$} & $\mathrm{n} / \mathrm{a}$ & $\mathrm{n} / \mathrm{a}$ & 2970 & $3890-4440$ & 27 \\
\hline & $\mathrm{n} / \mathrm{a}$ & $\mathrm{n} / \mathrm{a}$ & 3285 & 4360 & 28 \\
\hline $\mathrm{NH}_{2}-\mathrm{MIL}-101\left(\mathrm{Ti}{ }^{\mathrm{III}}, \mathrm{Al}\right)$ & $\mathrm{n} / \mathrm{a}$ & 200 & $2024-2146$ & $2792-2966$ & This work \\
\hline
\end{tabular}

* Cannot be activated, structural transformation to $\mathrm{NH}_{2}-\mathrm{MIL}-88(\mathrm{Sc})$ upon heating.

\section{Determination of cluster structure}

To determine the presence of organic species coordinating to the metal clusters of the thermally activated MOF, some amount of sample was digested in a $\mathrm{NaOD} / \mathrm{D}_{2} \mathrm{O}$ mixture and the obtained solution analyzed by ${ }^{1} \mathrm{H}-\mathrm{NMR}$. The spectra (Fig. S10) showed the characteristic signals of the aromatic protons of 2-aminoterephthalate $(7.3,6.9$ and $6.8 \mathrm{ppm})$, together with two singlets at 8.1 ppm and $1.9 \mathrm{ppm}$. Those singlets are attributed to sodium formate and dimethylamine, which are both products of the hydrolysis of DMF in NaOD. ${ }^{58}$ Since the integration of both signals gives a ratio close to $6\left(\mathrm{NH}\left(\mathrm{CH}_{3}\right)_{2} / \mathrm{HCOO}^{-}\right)$, it was deduced that those signals originated from DMF present inside the framework prior to digestion. It should be noted that the ratio of both integrals is always slightly inferior to 6 , which can be explained by the high volatility of dimethylamine. Quantification based on the integration of those signals, and especially the one of the non-volatile 
sodium formate, compared to the signal of the 2-aminoterephthalate linker allowed to determine that after activation slightly less than two molecules of DMF were present per trinuclear cluster (Table S5). Those results indicate very strong affinity between the DMF molecules used for the synthesis and the titanium metal centers. However, as the number of DMF molecules per cluster determined by ${ }^{1} \mathrm{H}-\mathrm{NMR}$ seemed to decrease when the MOF was activated at $150^{\circ} \mathrm{C}(1.4$ $\mathrm{DMF} /$ cluster $)$ instead of $100^{\circ} \mathrm{C}(1.7 \mathrm{DMF} /$ cluster $)$, it seems that thermal activation can at least remove some of the coordinated solvent, leading to the formation of coordinatively unsaturated metal centers (Figure 4, B.).

As no other species were detected by ${ }^{1} \mathrm{H}-\mathrm{NMR}$, we excluded the presence of organic anions balancing the residual positive charge of the clusters. Based on the results of ${ }^{1} \mathrm{H}-\mathrm{NMR}$, ICP analysis and $\mathrm{Cl}$ analysis by the Schöniger flask method (Table S6), we concluded that the composition of the activated $\mathrm{MOF}$ is $\mathrm{Ti}_{2.54} \mathrm{Al}_{0.46} \mathrm{OCl}(\mathrm{DMF})_{1.7}\left(\mathrm{BDCNH}_{2}\right)_{3}$. The charge balancing anion on the clusters is thus chloride, unlike for the MIL-101( $\left.\mathrm{Ti}^{\mathrm{III}}\right)$ MOF obtained by Mason et al., in which an ethoxide anion ensures the neutrality of the clusters (Figure 4, A.), that can be explained by the absence of ethanol in the reaction medium for our synthesis. ${ }^{27}$ Given the significant amount of Ti ${ }^{\mathrm{III}}$ compared to $\mathrm{Al}$ in the framework, it is reasonable to assume that some of the clusters composing the MOF are monometallic and of the $\mathrm{Ti}_{3} \mathrm{O}(\mathrm{Cl})(\mathrm{DMF})_{2}(\mathrm{COOR})_{6}$ type (Figure 4, B.), whereas some clusters are of the $\mathrm{Ti}_{2} \mathrm{AlO}(\mathrm{Cl})(\mathrm{DMF})_{2}(\mathrm{COOR})_{6}$ type. However, it should be noted that the presence of clusters with a higher number of aluminum atoms (i.e. $\mathrm{TiAl}_{2} \mathrm{O}$, or $\mathrm{Al}_{3} \mathrm{O}$ ) in the framework cannot be excluded based on the available data. The verification of this hypothesis requires highly specialized techniques, and would be very challenging due to the complex structure, high sensitivity of the MOF towards air, and the paramagnetic nature of $\mathrm{Ti}^{\mathrm{III}}$, and is therefore outside the scope of this work.

A.

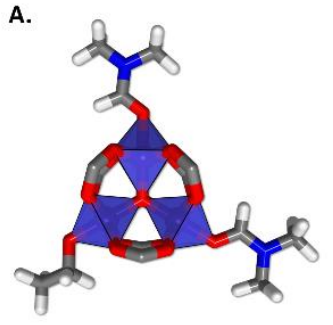

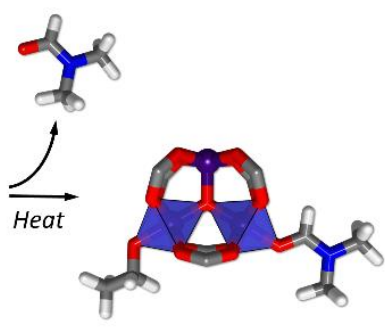

B.

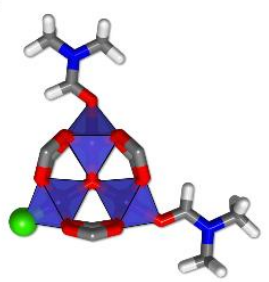

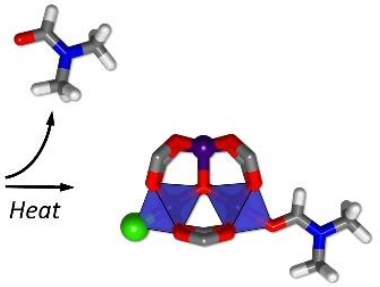


Figure 4. (A.) Structure of $\mathrm{Ti}_{3} \mathrm{O}(\mathrm{EtO})(\mathrm{DMF})_{2}(\mathrm{COOR})_{6}$ cluster composing MIL-101( $\left.{ }^{\mathrm{IIII}}\right)$ and activation mechanism as proposed by Mason et al. (part of the DMF can be replaced by THF). ${ }^{27}$ (B.) Structure of $\mathrm{Ti}_{3} \mathrm{OCl}(\mathrm{DMF})_{2}(\mathrm{COOR})_{6}$ cluster of $\mathrm{NH}_{2}-\mathrm{MIL}-101\left(\mathrm{Ti}^{\mathrm{III}}\right)$ obtained in this work and its activation. Color code: deep blue $=\mathrm{Ti}$; red $=\mathrm{O}$, grey $=\mathrm{C}$; marine blue $=\mathrm{N}$; white $=\mathrm{H}$; green $=\mathrm{Cl}$.

Thermogravimetric analysis of the sample after nitrogen physisorption analysis (Fig. S11) was performed to further confirm the above conclusions. Based on the determined structure, a weight loss of $73.1 \%$ is expected upon transformation of the framework into $\mathrm{TiO}_{2}$ and $\mathrm{Al}_{2} \mathrm{O}_{3}$. The experimental weight loss of the activated MOF after combustion is very close to the theoretical value and thus confirms our findings. Furthermore, the slightly higher weight loss on combustion for the DCM-washed sample activated at $100^{\circ} \mathrm{C}(73.11 \%)$ compared to the same sample activated at $150^{\circ} \mathrm{C}(72.68 \%)$ further indicates that higher activation temperatures allow for an increased removal of the coordinated DMF.

\section{Hydrogen sorption}

The hydrogen sorption isotherm of $\mathrm{NH}_{2}-\mathrm{MIL}-101$ ( $\left.\mathrm{Ti}^{\mathrm{III}}, \mathrm{Al}\right)$ at $77 \mathrm{~K}$ was recorded after activation at $100^{\circ} \mathrm{C}$. Interestingly, the uptake is quite steep at low pressures, especially when compared to $\mathrm{H}_{2}$ sorption in MIL-101( $\left.\mathrm{Ti}^{\mathrm{III}}\right)$ as previously described by Mason et al. ${ }^{27}$ This steep uptake might be indicative of interaction between the coordinatively unsaturated $\mathrm{Ti}^{\mathrm{III}}$ centers of the MOF and hydrogen. Remarkably, when normalized to the surface area, the uptake capacity of $\mathrm{NH}_{2}-\mathrm{MIL}-101\left(\mathrm{Ti}^{\mathrm{III}}, \mathrm{Al}\right)$ is nearly twice as high as for MIL-101( $\left.\mathrm{Ti}^{\mathrm{III}}\right)$, which further confirms that stronger interactions exist for this bimetallic amine-containing MOF. This improved adsorption performance might indicate that tuning the nature of the functionalities on the MOF's linkers might be an effective way of tuning the hydrogen sorption properties of $\mathrm{Ti}^{\mathrm{III}}$-based MOFs, in a similar way as to previous observations made for various MOFs based on other metals. ${ }^{59}$ 


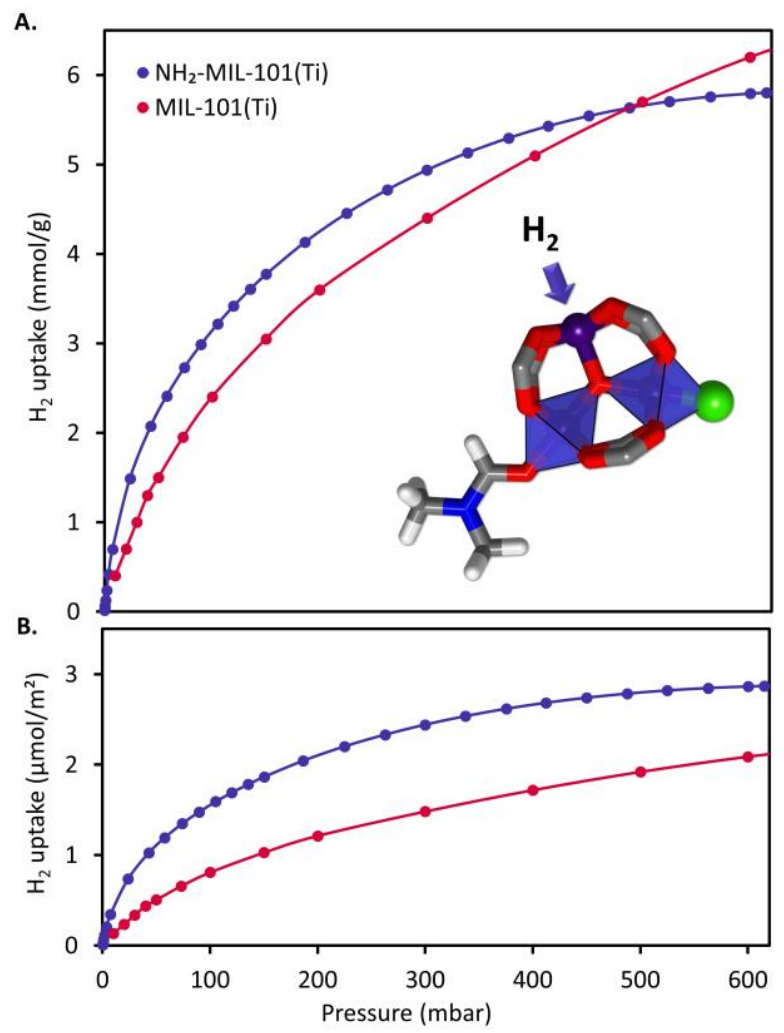

Figure 5. Hydrogen adsorption isotherms $(77 \mathrm{~K})$ of MIL-101 $\left(\mathrm{Ti}^{\mathrm{III}}\right)$ reported by Mason et al. ${ }^{27}\left(\mathrm{~S}_{\mathrm{BET}}=\right.$ $2970 \mathrm{~m}^{2} / \mathrm{g}$ ) and $\mathrm{NH}_{2}-\mathrm{MIL}-101$ ( $\left.\mathrm{Ti}^{\mathrm{III}}, \mathrm{Al}\right)$ from this work $\left(2024 \mathrm{~m}^{2} / \mathrm{g}\right.$ ), expressed in (A.) $\mathrm{mmol} \mathrm{H}_{2} / \mathrm{g}$ and (B.) relative to the BET surface area $\left(\mu \mathrm{mol} / \mathrm{m}^{2}\right)$. The inset shows the $\mathrm{Ti}^{\mathrm{III}}$ open-metal site on which $\mathrm{H}_{2}$ is likely to interact. 


\section{Conclusions}

We developed a synthesis strategy for obtaining bimetallic $\mathrm{NH}_{2}-\mathrm{MIL}-101\left(\mathrm{Ti}^{\mathrm{III}}, \mathrm{Al}\right)$ in a reproducible manner, by reacting $\mathrm{Ti}_{0.93} \mathrm{Al}_{0.07} \mathrm{Cl}_{3}(\mathrm{THF})_{3}$ with 4-aminoterephthalic acid in DMF at $130^{\circ} \mathrm{C}$, through a direct one pot synthesis strategy. All other reaction conditions screened with changes in used linkers or metals sources all yielded amorphous materials or structures that did not correspond to the MTN topology, or to low crystallinity materials. The thermal stability of this air sensitive MOF was determined to be around $200^{\circ} \mathrm{C}$ by means of thermogravimetric analysis and variable temperature PXRD. ${ }^{1} \mathrm{H}-\mathrm{NMR}$ and chloride determination by the Schöniger flask method revealed that the new MOF is composed of clusters having a $\mathrm{Cl}^{-}$charge neutralizing anion, of the $\mathrm{Ti}_{3} \mathrm{OCl}(\mathrm{DMF})_{2}\left(\mathrm{O}_{2} \mathrm{CR}\right)_{6}$ type, from which less than one DMF molecule can be thermally removed to create $\mathrm{Ti}^{\mathrm{III}}$ open metal sites. Surprisingly, the obtained $\mathrm{NH}_{2}-\mathrm{MIL}-101\left(\mathrm{Ti}^{\mathrm{III}}, \mathrm{Al}\right)$ has better affinity for hydrogen than the previously described MIL-101( $\left.\mathrm{Ti}^{\mathrm{III}}\right)$ material, indicating that linker functionalization can have a positive impact on the $\mathrm{H}_{2}$ sorption properties of $\mathrm{Ti}^{\mathrm{III}}$-based MOFs. We anticipate that the properties of $\mathrm{Ti}^{\mathrm{III}}$-containing $\mathrm{NH}_{2}-\mathrm{MIL}-101\left(\mathrm{Ti}^{\mathrm{III}}, \mathrm{Al}\right)$ could further be modulated through linker post-synthetic modification through amine chemistry, similarly to previous work on $\mathrm{NH}_{2}$-MIL-101(M) structures based on other metals, or by varying the nature and amount of the second metal. For example, the amount of $\mathrm{Al}$ could be increased to render the MOF less prone to degradation in the presence of oxygen. 


\section{Acknowledgements}

The authors thank the FNRS for the FRIA fellowship for T.S and the EQP and CdR projects (T.0169.13, U.N036.15, U.N022.19, J.0073.20). Jean-François Statsyns is acknowledged for technical support and for the hydrogen sorption measurements and Benjamin Van Meerbeek for the synthesis of the 1,3,5-tris(carboxyphenyl)benzene linker. 


\section{References}

(1) Moosavi, S. M.; Nandy, A.; Jablonka, K. M.; Ongari, D.; Janet, J. P.; Boyd, P. G.; Lee, Y.; Smit, B.; Kulik, H. J. Understanding the Diversity of the Metal-Organic Framework Ecosystem. Nat. Commun. 2020, 11 (1), 1-10. https://doi.org/10.1038/s41467-020-177558.

(2) Batten, S. R.; Champness, N. R.; Chen, X.-M.; Garcia-Martinez, J.; Kitagawa, S.; Öhrström, L.; O’Keeffe, M.; Paik Suh, M.; Reedijk, J. Terminology of Metal-Organic Frameworks and Coordination Polymers (IUPAC Recommendations 2013). Pure Appl. Chem. 2013, 85 (8), 1715-1724. https://doi.org/10.1351/PAC-REC-12-11-20.

(3) Kirchon, A.; Feng, L.; Drake, H. F.; Joseph, E. A.; Zhou, H. C. From Fundamentals to Applications: A Toolbox for Robust and Multifunctional MOF Materials. Chem. Soc. Rev. 2018, 47 (23), 8611-8638. https://doi.org/10.1039/c8cs00688a.

(4) Wang, B.; Xie, L. H.; Wang, X.; Liu, X. M.; Li, J.; Li, J. R. Applications of Metal-Organic Frameworks for Green Energy and Environment: New Advances in Adsorptive Gas Separation, Storage and Removal. Green Energy Environ. 2018, 3 (3), 191-228. https://doi.org/10.1016/j.gee.2018.03.001.

(5) Pascanu, V.; González Miera, G.; Inge, A. K.; Martín-Matute, B. Metal-Organic Frameworks as Catalysts for Organic Synthesis: A Critical Perspective. J. Am. Chem. Soc. 2019, 141 (18), 7223-7234. https://doi.org/10.1021/jacs.9b00733.

(6) Wei, Y. S.; Zhang, M.; Zou, R.; Xu, Q. Metal-Organic Framework-Based Catalysts with Single Metal Sites. Chem. Rev. 2020, $120 \quad$ (21), 12089-12174. https://doi.org/10.1021/acs.chemrev.9b00757.

(7) Li, H.; Wang, K.; Sun, Y.; Lollar, C. T.; Li, J.; Zhou, H. C. Recent Advances in Gas Storage and Separation Using Metal-Organic Frameworks. Mater. Today 2018, 21 (2), 108-121. https://doi.org/10.1016/j.mattod.2017.07.006.

(8) Schlenker, J. L.; Dwyer, F. G.; Jenkins, E. E.; Rohrbaugh, W. J.; Kokotailo, G. T.; Meier, W. M. Crystal Structure of a Synthetic High Silica Zeolite-ZSM-39. Nature 1981, 294, $340-342$. 
(9) Fang, Q.; Zhu, G.; Xue, M.; Sun, J.; Wei, Y.; Qui, S.; Xu, R. A Metal-Organic Framework with the Zeolite MTN Topology Containing Large Cages of Volume 2.5 Nm3. Angew. Chemie - Int. Ed. 2005, 44 (25), 3845-3848. https://doi.org/10.1002/anie.200462260.

(10) Lu, W.; Wei, Z.; Gu, Z. Y.; Liu, T. F.; Park, J.; Park, J.; Tian, J.; Zhang, M.; Zhang, Q.; Gentle, T.; Bosch, M.; Zhou, H. C. Tuning the Structure and Function of Metal-Organic Frameworks via Linker Design. Chem. Soc. Rev. 2014, 43 (16), 5561-5593. https://doi.org/10.1039/c4cs00003j.

(11) Férey, G.; Serre, C.; Mellot-Draznieks, C.; Millange, F.; Surblé, S.; Dutour, J.; Margiolaki, I. A Hybrid Solid with Giant Pores Prepared by a Combination of Targeted Chemistry, Simulation, and Powder Diffraction. Angew. Chemie - Int. Ed. 2004, 43 (46), 6296-6301. https://doi.org/10.1002/anie.200460592.

(12) Llewellyn, P. L.; Bourrelly, S.; Serre, C.; Vimont, A.; Daturi, M.; Hamon, L.; Weireld, G. De; Chang, J.; Hong, D.; Hwang, Y. K.; Jhung, S. H. High Uptakes of CO 2 and CH 4 in Mesoporous Metal s Organic Frameworks MIL-100 and MIL-101. 2008, No. 18, 72457250.

(13) Yoon, J. W.; Seo, Y. K.; Hwang, Y. K.; Chang, J. S.; Leclerc, H.; Wuttke, S.; Bazin, P.; Vimont, A.; Daturi, M.; Bloch, E.; Llewellyn, P. L.; Serre, C.; Horcajada, P.; Grenèche, J. M.; Rodrigues, A. E.; Férey, G. Controlled Reducibility of a Metal-Organic Framework with Coordinatively Unsaturated Sites for Preferential Gas Sorption. Angew. Chemie - Int. Ed. 2010, 49 (34), 5949-5952. https://doi.org/10.1002/anie.201001230.

(14) Barbosa, A. D. S.; Julião, D.; Fernandes, D. M.; Peixoto, A. F.; Freire, C.; de Castro, B.; Granadeiro, C. M.; Balula, S. S.; Cunha-Silva, L. Catalytic Performance and Electrochemical Behaviour of Metal-Organic Frameworks: MIL-101(Fe) versus NH2-MIL101(Fe). Polyhedron 2017, 127, 464-470. https://doi.org/10.1016/j.poly.2016.10.032.

(15) Volkringer, C.; Popov, D.; Loiseau, T.; Férey, G.; Burghammer, M.; Riekel, C.; Haouas, M.; Taulelle, F. Synthesis, Single-Crystal X-Ray Microdiffraction, and NMR Characterizations of the Giant Pore Metal-Organic Framework Aluminum Trimesate MIL100. Chem. Mater. 2009, 21 (24), 5695-5697. https://doi.org/10.1021/cm901983a.

(16) Serra-Crespo, P.; Ramos-Fernandez, E. V.; Gascon, J.; Kapteijn, F. Synthesis and 
Characterization of an Amino Functionalized MIL-101(Al): Separation and Catalytic Properties. Chem. Mater. 2011, 23 (10), 2565-2572. https://doi.org/10.1021/cm103644b.

(17) Steenhaut, T.; Filinchuk, Y.; Hermans, S. Aluminium-Based MIL-100(Al) and MIL-101(Al) Metal-Organic Frameworks, Derivative Materials and Composites: Synthesis, Structure, Properties and Applications. J. Mater. Chem. A 2021, 9, 21483-21509. https://doi.org/10.1039/D1TA04444C.

(18) Lieb, A.; Leclerc, H.; Devic, T.; Serre, C.; Margiolaki, I.; Mahjoubi, F.; Lee, J. S.; Vimont, A.; Daturi, M.; Chang, J. S. MIL-100(V) - A Mesoporous Vanadium Metal Organic Framework with Accessible Metal Sites. Microporous Mesoporous Mater. 2012, 157, 1823. https://doi.org/10.1016/j.micromeso.2011.12.001.

(19) Carson, F.; Su, J.; Platero-Prats, A. E.; Wan, W.; Yun, Y.; Samain, L.; Zou, X. Framework Isomerism in Vanadium Metal-Organic Frameworks: MIL-88B(V) and MIL-101(V). Cryst. Growth Des. 2013, 13 (11), 5036-5044. https://doi.org/10.1021/cg4012058.

(20) Dou, Z.; Cai, J.; Cui, Y.; Yu, J.; Xia, T.; Yang, Y.; Qian, G. Preparation and Gas Separation Properties of Metal-Organic Framework Membranes. Zeitschrift fur Anorg. und Allg. Chemie 2015, 641 (5), 792-796. https://doi.org/10.1002/zaac.201400574.

(21) Reinsch, H.; Stock, N. Formation and Characterisation of Mn-MIL-100. CrystEngComm 2013, 15 (3), 544-550. https://doi.org/10.1039/c2ce26436f.

(22) Mitchell, L.; Gonzalez-Santiago, B.; Mowat, J. P. S.; Gunn, M. E.; Williamson, P.; Acerbi, N.; Clarke, M. L.; Wright, P. A. Remarkable Lewis Acid Catalytic Performance of the Scandium Trimesate Metal Organic Framework MIL-100(Sc) for C-C and C=N BondForming Reactions. Catal. Sci. Technol. 2013, 3 (3), 606-617. https://doi.org/10.1039/c2cy20577g.

(23) Castells-Gil, J.; M. Padial, N.; Almora-Barrios, N.; Da Silva, I.; Mateo, D.; Albero, J.; García, H.; Martí-Gastaldo, C. De Novo Synthesis of Mesoporous Photoactive Titanium(Iv)-Organic Frameworks with MIL-100 Topology. Chem. Sci. 2019, 10 (15), 4313-4321. https://doi.org/10.1039/C8SC05218B.

(24) Giménez-Marqués, M.; Santiago-Portillo, A.; Navalón, S.; Álvaro, M.; Briois, V.; Nouar, F.; Garcia, H.; Serre, C. Exploring the Catalytic Performance of a Series of Bimetallic MIL- 
100(Fe, Ni) MOFs. J. Mater. Chem. A 2019, 7, 20285-20292. https://doi.org/10.1039/C9TA01948K.

(25) Castells-Gil, J.; M. Padial, N.; Almora-Barrios, N.; Gil-San-Millán, R.; Romero-Ángel, M.; Torres, V.; da Silva, I.; Vieira, B. C. J.; Waerenborgh, J. C.; Jagiello, J.; Navarro, J. A. R.; Tatay, S.; Martí-Gastaldo, C. Heterometallic Titanium-Organic Frameworks as Dual-Metal Catalysts for Synergistic Non-Buffered Hydrolysis of Nerve Agent Simulants. Chem 2020, 6 (11), 3118-3131. https://doi.org/10.1016/j.chempr.2020.09.002.

(26) Steenhaut, T.; Hermans, S.; Filinchuk, Y. Green Synthesis of a Large Series of Bimetallic MIL-100(Fe,M) MOFs. New J. Chem. 2020, 44, 3847-3855. https://doi.org/10.1039/d0nj00257g.

(27) Mason, J. A.; Darago, L. E.; Lukens, W. W.; Long, J. R. Synthesis and O2 Reactivity of a Titanium(III) Metal-Organic Framework. Inorg. Chem. 2015, 54 (20), 10096-10104. https://doi.org/10.1021/acs.inorgchem.5b02046.

(28) Antonio, A. M.; Rosenthal, J.; Bloch, E. D. Electrochemically Mediated Syntheses of Titanium(III)-Based Metal-Organic Frameworks. J. Am. Chem. Soc. 2019, 141 (29), 1138311387. https://doi.org/10.1021/jacs.9b05035.

(29) Brozek, C. K.; Dincă, M. Ti 3+ -, V 2+/3+ -, Cr 2+/3+ -, Mn 2+ -, and Fe 2+ -Substituted MOF-5 and Redox Reactivity in Cr- and Fe-MOF-5. J. Am. Chem. Soc. 2013, 135 (34), 12886-12891. https://doi.org/10.1021/ja4064475.

(30) Bueken, B.; Vermoortele, F.; Vanpoucke, D. E. P.; Reinsch, H.; Tsou, C. C.; Valvekens, P.; De Baerdemaeker, T.; Ameloot, R.; Kirschhock, C. E. A.; Van Speybroeck, V.; Mayer, J. M.; De Vos, D. A Flexible Photoactive Titanium Metal-Organic Framework Based on a [TiIV3(M3-O)(O)2(COO)6] Cluster. Angew. Chemie - Int. Ed. 2015, 54 (47), 13912-13917. https://doi.org/10.1002/anie.201505512.

(31) Zou, L.; Feng, D.; Liu, T. F.; Chen, Y. P.; Yuan, S.; Wang, K.; Wang, X.; Fordham, S.; Zhou, H. C. A Versatile Synthetic Route for the Preparation of Titanium Metal-Organic Frameworks. Chem. Sci. 2016, 7 (2), 1063-1069. https://doi.org/10.1039/c5sc03620h.

(32) Ji, P.; Song, Y.; Drake, T.; Veroneau, S. S.; Lin, Z.; Pan, X.; Lin, W. Titanium(III)-Oxo Clusters in a Metal-Organic Framework Support Single-Site Co(II)-Hydride Catalysts for 
Arene Hydrogenation. J. Am. Chem. Soc. 2018, 140 (1), 433-440. https://doi.org/10.1021/jacs.7b11241.

(33) Kang, S.; Klebanoff, L. E.; Baker, A. A.; Cowgill, D. F.; Stavila, V.; Lee, J. R. I.; Nielsen, M. H.; Ray, K. G.; Liu, Y.; Wood, B. C. ScienceDirect Assessing the Reactivity of TiCl 3 and TiF 3 with Hydrogen. Int. J. Hydrogen Energy 2018, 43, 14507-14519. https://doi.org/10.1016/j.ijhydene.2018.05.128.

(34) Liu, N.; Xu, M.; Yang, Y.; Zhang, S.; Zhang, J.; Wang, W.; Zheng, L.; Hong, S.; Wei, M. $\mathrm{Au} \delta--\mathrm{O} v-\mathrm{Ti} 3+$ Interfacial Site : Catalytic Active Center toward Low- Temperature Water Gas Shift Reaction. ACS Catal. 2019, 9, 2707-2717. https://doi.org/10.1021/acscatal.8b04913.

(35) Yang, X.; Qu, J.; Wang, L.; Luo, J. In-Plasma-Catalysis for NO x Degradation by Ti 3 +. RSC Adv. 2021, 11, 24144-24155. https://doi.org/10.1039/d1ra02847b.

(36) Qing, Y.; Li, Y.; Li, W.; Yao, H. Ti3+ Self-Doped Dark TiO2 Nanoparticles with Tunable and Unique Dielectric Properties for Electromagnetic Applications. J. Mater. Chem. C 2021, 9, 1205-1214. https://doi.org/10.1039/d0tc05112h.

(37) Lin, Y.; Kong, C.; Chen, L. Amine-Functionalized Metal-Organic Frameworks: Structure, Synthesis and Applications. RSC Adv. 2016, 6 (39), 32598-32614. https://doi.org/10.1039/c6ra01536k.

(38) Xu, C.; Fang, R.; Luque, R.; Chen, L.; Li, Y. Functional Metal-Organic Frameworks for Catalytic Applications. Coord. Chem. Rev. 2019, 388, 268-292. https://doi.org/10.1016/j.ccr.2019.03.005.

(39) Cohen, S. M. Postsynthetic Methods for the Functionalization of Metal-Organic Frameworks. Chem. Rev. 2012, 112 (2), 970-1000. https://doi.org/10.1021/cr200179u.

(40) Wu, S.; Chen, L.; Yin, B.; Li, Y. "Click" Post-Functionalization of a Metal-Organic Framework for Engineering Active Single-Site Heterogeneous Ru(III) Catalysts. Chem. Commun. 2015, 51 (48), 9884-9887. https://doi.org/10.1039/c5cc02741a.

(41) Kalaj, M.; Cohen, S. M. Postsynthetic Modification: An Enabling Technology for the Advancement of Metal-Organic Frameworks. ACS Cent. Sci. 2020, 6 (7), 1046-1057. https://doi.org/10.1021/acscentsci.0c00690. 
(42) Zou, L.; Feng, D.; Liu, T.-F.; Chen, Y.-P.; Yuan, S.; Wang, K.; Wang, X.; Fordhama, S.; Zhou, H.-C. A Versatile Synthetic Route for the Preparation of Titanium Metal-Organic Frameworks. Chem. Sci. 2016, 7, 1063-1069. https://doi.org/10.1039/c5sc03620h.

(43) Jones, N. A.; Liddle, S. T.; Wilson, C.; Arnold, P. L. Titanium(III) Alkoxy-N-Heterocyclic Carbenes and a Safe, Low-Cost Route to TiCl3(THF)3. Organometallics 2007, 26 (3), 755757. https://doi.org/10.1021/om060486d.

(44) Morel, F. L.; Ranocchiari, M.; Bokhoven, J. A. Van. Synthesis and Characterization of Phosphine-Functionalized Metal - Organic Frameworks Based on MOF - 5 and MIL-101 Topologies. Ind. Eng. Chem. Res. 2014, 53 (22), 9120-9127.

(45) Rana, U.; Mondal, S.; Sannigrahi, J.; Sukul, P. K.; Amin, M. A.; Majumdarb, S.; Malik, S. Aromatic Bi-, Tri- and Tetracarboxylic Acid Doped Polyaniline Nanotubes: Effect on Morphologies and Electrical Transport Properties. J. Mater. Chem. C 2014, 2, 3382-3389. https://doi.org/10.1039/c3tc32152e.

(46) Rubin, H. N.; Reynolds, M. M. Functionalization of Metal-Organic Frameworks To Achieve Controllable Wettability. Inorg. Chem. 2017, 56 (9), 5266-5274. https://doi.org/10.1021/acs.inorgchem.7b00373.

(47) Yoon, J. H.; Choi, S. B.; Oh, Y. J.; Seo, M. J.; Jhon, Y. H.; Lee, T. B.; Kim, D.; Choi, S. H.; Kim, J. A Porous Mixed-Valent Iron MOF Exhibiting the Acs Net: Synthesis, Characterization and Sorption Behavior of $\mathrm{Fe} 3 \mathrm{O}(\mathrm{F} 4 \mathrm{BDC}) 3(\mathrm{H} 2 \mathrm{O}) 3 \cdot(\mathrm{DMF}) 3.5$. Catal. Today 2007, 120 (3-4 SPEC. ISS.), 324-329. https://doi.org/10.1016/j.cattod.2006.09.003.

(48) Goesten, M. G.; Stavitski, E.; Juan-Alcañiz, J.; Martiñez-Joaristi, A.; Petukhov, A. V.; Kapteijn, F.; Gascon, J. Small-Angle X-Ray Scattering Documents the Growth of MetalOrganic Frameworks. Catal. Today 2013, 205, 120-127. https://doi.org/10.1016/j.cattod.2012.08.044.

(49) Steenhaut, T.; Filinchuk, Y.; Hermans, S. Aluminium-Based MIL-100(Al) and MIL-101(Al) Metal-Organic Frameworks, Derivative Materials and Composites: Synthesis, Structure, Properties and Applications. J. Mater. Chem. A 2021, 9, 21483-21509. https://doi.org/10.1039/D1TA04444C.

(50) Steenhaut, T.; Grégoire, N.; Barozzino-Consiglio, G.; Filinchuk, Y.; Hermans, S. 
Mechanochemical Defect Engineering of HKUST-1 and Impact of the Resulting Defects on Carbon Dioxide Sorption and Catalytic Cyclopropanation. RSC Adv. 2020, 10 (34), 1982219831. https://doi.org/10.1039/c9ra10412g.

(51) Ma, J.; Kalenak, A. P.; Wong-Foy, A. G.; Matzger, A. J. Rapid Guest Exchange and UltraLow Surface Tension Solvents Optimize Metal-Organic Framework Activation. Angew. Chemie - Int. Ed. 2017, 56 (46), 14618-14621. https://doi.org/10.1002/anie.201709187.

(52) Babar, M.; Mubashir, M.; Mukhtar, A.; Saqib, S.; Ullah, S.; Bustam, M. A.; Show, P. L. Sustainable Functionalized Metal-Organic Framework NH2-MIL-101(Al) for CO2 Separation under Cryogenic Conditions. Environ. Pollut. 2021, 279, 116924. https://doi.org/10.1016/j.envpol.2021.116924.

(53) Chen, M. L.; Zhou, S. Y.; Xu, Z.; Ding, L.; Cheng, Y. H. Metal-Organic Frameworks of MIL-100(Fe, Cr) and MIL-101(Cr) for Aromatic Amines Adsorption from Aqueous Solutions. Molecules 2019, 24 (20). https://doi.org/10.3390/molecules24203718.

(54) Burrows, A. D.; Jiang, D.; Keenan, L. L.; Burrows, A. D.; Edler, K. J. ChemComm Synthesis and Post-Synthetic Modification of MIL-101 ( $\mathrm{Cr}$ ) -NH 2 via a Tandem Diazotisation Process W. Chem. Comm. 2012, 48, 12053-12055. https://doi.org/10.1039/c2cc36344e.

(55) Taha, A. A.; Huang, L.; Ramakrishna, S.; Liu, Y. MOF [NH2-MIL-101(Fe)] as a Powerful and Reusable Fenton-like Catalyst. J. Water Process Eng. 2020, 33 (November 2019), 101004. https://doi.org/10.1016/j.jwpe.2019.101004.

(56) Karimi Alavijeh, R.; Akhbari, K. Biocompatible MIL-101(Fe) as a Smart Carrier with High Loading Potential and Sustained Release of Curcumin. Inorg. Chem. 2020, 59 (6), 35703578. https://doi.org/10.1021/acs.inorgchem.9b02756.

(57) Santiago, B. G.; A. Synthesis and Properties of Scandium Carboxylate Metal-Organic Frameworks; University of St Andrews, 2015.

(58) Buncel, E.; Symons, E. A. The Inherent Instability of Dimethylformamide-Water Systems Containing Hydroxide Ion. J. Chem. Soc. D Chem. Commun. 1970, No. 3, 164-165. https://doi.org/10.1039/C29700000164.

(59) Deng, H.; Doonan, C. J.; Furukawa, H.; Ferreira, R. B.; Towne, J.; Knobler, C. B.; Wang, 
B.; Yaghi, O. M. Multiple Functional Groups of Varying Ratios in Metal-Organic $\begin{array}{llllll}\text { Frameworks. } & \text { Science } & \text { (80-. } & \text { ). } & \text { 2010, } 327 & \text { (5967), }\end{array}$ https://doi.org/10.1126/science.1181761. 